\title{
Angiotensinogen and Angiotensin-Converting Enzyme Genotypes, and Day and Night Blood Pressures in Elderly Japanese Hypertensives
}

\author{
Kazuomi Kario, Satoshi Hoshide, Yuji Umeda, Yoko Sato, Uichi Ikeda, Shinichi Nishiuma*, \\ Masafumi Matsuo*, and Kazuyuki Shimada
}

\begin{abstract}
There are inconsistent reports that the angiotensinogen (ATG) variant Met $^{235} \rightarrow$ Thr (T235) allele and angiotensin-converting enzyme (ACE) insertion/deletion (I/D) variants are associated with hypertension and related target organ damage. Both high blood pressure (BP) and abnormal diurnal BP variation patterns are related to target organ damage, but it is not known whether the above genetic variants of the renin-angiotensin system are related to $24 \mathrm{~h} \mathrm{BP}$ and the diurnal BP pattern in Japanese. We studied the association of the ATG T235 allele and ACE D allele with $24 \mathrm{~h}$ BP and diurnal BP variation in 235 of 262 consecutive untreated (or off medication) elderly Japanese hypertensives who underwent $24 \mathrm{~h}$ ambulatory BP monitoring. There was no significant association between the T235 or ACE D allele with office BP, but the T235 allele was significantly associated with $24 \mathrm{~h} \mathrm{BP}$ and day BP, and the D allele was significantly associated with increased $24 \mathrm{~h}$ BP, day BP, and night BP. There were no effects of the T235 or D alleles on any BP parameters. Those with white-coat hypertension had a significantly lower T235 allele frequency $(0.68)$ than those with sustained hypertension $(0.79, p=0.010)$, but the difference in $D$ allele frequency was marginal $(0.30 \mathrm{vs} .0 .38, p=0.057)$. In conclusion, in elderly Japanese hypertensive individuals, both the ATG T 235 and ACE D alleles are associated with increased $24 \mathrm{~h}$ BP and day BP, while only the ACE D allele is associated with increased night BP. (Hypertens Res 1999; 22: 95-103)
\end{abstract}

Key Words: angiotensinogen gene, angiotensin-converting-enzyme gene, $24 \mathrm{~h}$ blood pressure, diurnal blood pressure variation, elderly Japanese, white-coat hypertension

The renin-angiotensin system regulates vascular tone, cardiovascular remodeling, and salt and water homeostasis, and this system is also closely involved in the physiologic regulation of blood pressure (BP). Thus, genes that influence the renin-angiotensin system are potential etiologic agents in hypertension and related cardiovascular disease. The plasma level of angiotensinogen (ATG), a key component of this system, is correlated with $\operatorname{BP}(1,2)$. The human ATG gene has been cloned, sequenced, and localized to $1 \mathrm{q} 45$ by in situ hybridization $(3,4)$. A positive association between hypertension and the molecular variant of the ATG gene that encodes threonine instead of methionine at position 235 (T235) has been reported in Caucasians and Japanese (5-9), but two other recent studies did not support this finding $(10,11)$. We recently clarified that the ATG T235 allele is more common in Japanese than in Caucasians, and we identified it as a predisposing factor for hypertension in two Japanese community-dwelling populations (12).

Angiotensin-converting enzyme (ACE) variant, encoding an intronic deletion of a 289 bp Alu sequence, is reported to be associated with cardiovascular disease in Caucasians and in Japanese (13-16). However, this ACE insertion/deletion (I/D) polymorphism was reportedly unrelated to essential hypertension in Caucasians $(13,14,16-19)$, although at least one report does not support this finding (20). This discrepancy is also found in studies on Japanese $(21,22)$.

These different finding might be due to the definition of hypertension based on office BP. Hypertensive patients diagnosed based on office BP would include some white-coat hypertensives, whose BP in non-medical environments is normal (23). In addition to high BP itself, abnormal diurnal BP variation has been reported to be associated with target

From the Department of Cardiology, Jichi Medical School, Tochigi, Japan, * Division of Genetics, International Center of Medical Research, Kobe University School of Medicine, Kobe, Japan.

This study was supported in part by the Jichi Medical School Young Investigator Award (KK), the Scientific Research Grant-in-Aid 09670746 (KK) from the Ministry of Education of the Government of Japan, the Kimura Memorial Heart Foundation Grant for Research on Autonomic Nervous System and Hypertension (KK), grants-in-aid (KK) from the Foundation for the Development of the Community (1992-1997) and from the Foudation for Total Health Promotion. Address for Reprints: Kazuomi Kario, M.D., Ph.D., Cardiovascular Center, Department of Medicine, Cornell University Medical College / The New York Presbyterian Hospital, 520 East 70th Street-Starr 437, New York, NY 10021, USA. Received January 6, 1999; accepted in revised form March 31, 1999. 
organ damage and poor prognosis in hypertensive patients (24-27). Accordingly, we investigated the association of the ATG T235 allele and ACE D allele with $24 \mathrm{~h} \mathrm{BP}$ and diurnal BP variation in 235 of 262 consecutive elderly Japanese hypertensives in whom $24 \mathrm{~h}$ ambulatory BP monitoring (ABPM) was performed.

\section{Methods}

\section{Subjects}

We studied 385 consecutive elderly hypertensive outpatients aged $\geq 60 \mathrm{yr}$. Hypertension was diagnosed when the average (of 3 or more occasions) systolic BP (SBP) was $\geq 140 \mathrm{mmHg}$ and/or the average diastolic BP (DBP) was $\geq 90 \mathrm{mmHg}(28)$, or when the patient was receiving antihypertensive therapy. BP was measured in the sitting position using an automated sphygmomanometer (BP103N-II, Nippon Colin, Co., Ltd., Komaki, Japan) after the patient rested for at least $5 \mathrm{~min}$. We took a detailed history of the duration of hypertension and cardiovascular complications such as stroke or coronar$\mathrm{y}$ artery disease (myocardial infarction and angina pectoris) from all participants, and conducted a physical examination and laboratory studies including blood and urine tests, chest X-ray, and resting electrocardiography. We excluded from this study 67 patients with renal failure, hepatic damage (serum level of creatinine $>1.5 \mathrm{mg} / \mathrm{dl}$, blood urea nitrogen level $>30 \mathrm{mg} / \mathrm{dl}$, or aspartate aminotransferase or alanine aminotransferase level $>40$ IU/l), or possible overt diabetes mellitus (fasting glucose $>140 \mathrm{mg} / \mathrm{dl}$ and/or hemoglobin $\mathrm{A}_{1 \mathrm{c}}>6.4 \%$ ) or with present or previous coronary artery disease, stroke, congestive heart failure, atrial fibrillation, or malignancy, since these complications per se have been reported to affect BP levels and the diurnal $\mathrm{BP}$ variation. The remaining 318 hypertensive subjects met the criteria for World Health Organization (WHO) stage I or II hypertension, and had no indication in their history or routine laboratory test results of secondary hypertension. No antihypertensive therapy was administered in 104 (33\%) of the 318 hypertensive patients for at least 1 mo before examination. All remaining treated patients were asked to discontinue their antihypertensive therapy 7-14 d before examination, but $56(18 \%)$ were not able to do so. Finally, ABPM was performed in 262 hypertensive subjects who were not under antihypertensive therapy for at least $7 \mathrm{~d}$ before examination.

To compare the gene frequencies of ATG M235T and ACE I/D alleles of these hypertensive subjects with those of normotensive subjects, we analyzed some of our previous data $(12,16)$. These data were acquired on normotensive community-dwelling subjects who participated in annual examinations conducted as a part of the Jichi Medical School Cohort Study $(29,30)$. As the frequencies of ATG T235 and ACE D alleles are widely different in different geographic areas even within Japan (12, $16,31)$, we analyzed the data exclusively for normotensive subjects residing in the same area (Hoku- dan district on the Awaji Island) as the hypertensive patients of the present study.

Smokers were defined as current smokers. The body mass index was calculated as weight $(\mathrm{kg}) /$ height $(\mathrm{m})^{2}$. Left ventricular hypertrophy diagnosed by electrocardiography (ECG-LVH) was defined as abnormally high voltages of $Q R S$ complexes $(R$ in V5 plus $\mathrm{S}$ in V1 greater than $3.5 \mathrm{mV}$ ) associated either with flat $\mathrm{T}$ waves (less than $10 \%$ of $\mathrm{R}$ ) or with ST segment depression and diphasic $\mathrm{T}$ waves (32).

This collaborative study was approved by our institutional review committee, and informed consent was obtained from each subject studied. The measurement of clinical and metabolic characteristics and blood sampling of the studied subjects were performed at independent institutes from those at which the ACE gene and ATG gene identification were carried out.

\section{$24 h A B P M$}

Noninvasive ABPM was carried out on week-days with an automatic ambulatory BP monitor with gaspowered cuff inflation (ABPM-630, Nippon Colin Co., Komaki, Aichi, Japan), which recorded BP and heart rate every $30 \mathrm{~min}$ for $24 \mathrm{~h}$. The accuracy of this device was previously validated (33). The ambulatory data used were those obtained by the oscillometric method. Each subject kept an activities journal in which he or she recorded information about the exact times of falling asleep and waking up. Re-examination was performed in 35 hypertensive patients whose BP data were not usable due to the presence of artifacts in more than $10 \%$ of the total measurements. We excluded from this study 27 subjects who complained of sleep disturbance during ambulatory BP monitoring. Thus data were obtained on 235 subjects.

Definitions of White-Coat Hypertension, Sustained Hypertension, Extreme-Dippers, Dippers, and NonDippers

The night BP was defined as the mean BP from the time at which the patient went to bed until the time of awakening, and the day BP was defined as the mean BP during the remaining portion of the day $(25,27)$. Hypertensive patients with $24 \mathrm{~h}$ SBP $\geq 135$ $\mathrm{mmHg}$ and/or $24 \mathrm{~h}$ DBP $\geq 80 \mathrm{mmHg}$ were defined as having sustained hypertension $(n=161)$ and those with $24 \mathrm{~h}$ BP below these levels as having white-coat hypertension $(n=74)$, as described previously $(25,27)$. Then, the nocturnal SBP change was calculated as (day SBP - night SBP) /day SBP (27). In total 161 hypertensive patients were subclassified based on the nocturnal SBP fall as follows: 18 extreme-dippers with $\geq 20 \%$ nocturnal reduction of SBP; 66 dippers with $\geq 10 \%$ but $<20 \%$ reduction; and 77 non-dippers with $<10 \%$ reduction (higher night SBP level than day SBP).

\section{Determination of ATG M235T Genotype}

Genomic DNA was extracted from citrated whole blood using salt/chloroform by modification of a previously described method (34). Enzymatic am- 
Table 1. Office and $24 \mathrm{~h}$ BP in Hypertensives with Different ATG T/M Genotypes

\begin{tabular}{|c|c|c|c|c|}
\hline & & MM & MT & TT \\
\hline \multicolumn{2}{|l|}{ Number } & 10 & 97 & 128 \\
\hline \multicolumn{2}{|l|}{ Age $(y r)$} & $69(9.3)$ & $70(9.2)$ & $70(9.7)$ \\
\hline \multicolumn{2}{|c|}{ Male $(\%)$} & 30 & 31 & 36 \\
\hline \multicolumn{2}{|c|}{ Body mass index $\left(\mathrm{kg} / \mathrm{m}^{2}\right)$} & $23.5(2.1)$ & $23.2(3.5)$ & $24.4(3.2)^{\dagger}$ \\
\hline \multicolumn{2}{|c|}{ ECG-LVH $(\%)$} & 10 & 32 & 20 \\
\hline \multicolumn{2}{|c|}{ Smokers $(\%)$} & 20 & 30 & 33 \\
\hline \multicolumn{5}{|c|}{ Family history of hypertension } \\
\hline \multicolumn{2}{|c|}{ Either parent $(\%)$} & 50 & 36 & 43 \\
\hline \multicolumn{2}{|c|}{ Both parents (\%) } & 10 & 8 & 13 \\
\hline \multicolumn{5}{|c|}{ Family history of cardiovascular disease } \\
\hline \multicolumn{2}{|c|}{ Either parent $(\%)$} & 20 & 14 & 27 \\
\hline \multirow[t]{3}{*}{ Office } & SBP (mmHg) & $156(16)$ & $163(18)$ & $165(20)$ \\
\hline & $\mathrm{DBP}(\mathrm{mmHg})$ & $91(8.0)$ & $98(12)$ & $94(13)$ \\
\hline & $\operatorname{HR}(/ \min )$ & $84(6.9)$ & $78(15)$ & $78(14)$ \\
\hline \multirow[t]{3}{*}{ 24-h } & $\mathrm{SBP}(\mathrm{mmHg})$ & $130(12)$ & $140(16)^{*}$ & $144(12) * *$ \\
\hline & $\mathrm{DBP}(\mathrm{mmHg})$ & $75(6.8)$ & $79(10)$ & $81(10)$ \\
\hline & $\operatorname{HR}(/ \min )$ & $72(5.7)$ & $71(7.8)$ & $71(7.8)$ \\
\hline \multirow[t]{3}{*}{ Day } & $\mathrm{SBP}(\mathrm{mmHg})$ & $133(14)$ & $144(17)^{*}$ & $150(13) * * *, \dagger$ \\
\hline & $\mathrm{DBP}(\mathrm{mmHg})$ & $78(7.6)$ & $81(11)$ & $85(9.2)^{*, \dagger}$ \\
\hline & $\operatorname{HR}(/ \min )$ & $77(6.5)$ & $77(8.4)$ & $77(8.5)$ \\
\hline \multirow[t]{3}{*}{ Night } & $\mathrm{SBP}(\mathrm{mmHg})$ & $124(13)$ & $132(19)$ & $135(15)$ \\
\hline & $\mathrm{DBP}(\mathrm{mmHg})$ & $70(8.2)$ & $73(11)$ & $74(9.8)$ \\
\hline & $\operatorname{HR}(/ \min )$ & $63(6.0)$ & $61(7.6)$ & $62(9.0)$ \\
\hline \multirow[t]{3}{*}{ Night-lowest } & $\mathrm{SBP}(\mathrm{mmHg})$ & $111(13)$ & 117 (18) & $116(20)$ \\
\hline & $\mathrm{DBP}(\mathrm{mmHg})$ & $62(11)$ & $66(13)$ & $66(11)$ \\
\hline & $\operatorname{HR}(/ \min )$ & $63(7.3)$ & $63(11)$ & $64(11)$ \\
\hline
\end{tabular}

Data for age and metabolic variables are shown as the mean (SD). M, ATG M235; T, ATG T235; SBP, systolic blood pressure; DBP, diastolic blood pressure; ECG-LVH, left ventricular hypertrophy detected by electrocardiography; BP, blood pressure; HR, heart rate. ${ }^{*} p<0.05,{ }^{* *} p<0.01,{ }^{* * *} p<0.001, v s$. MM genotype; ${ }^{\dagger} p<0.01, v s$. MT genotype by Scheffe's $F$-test.

plification of DNA was performed by the polymerase chain reaction (PCR) using $1 \mu \mathrm{l}$ DNA extract and thermostable Taq polymerase (Takara Biochemical, Kyoto, Japan) according to the manufacturer's instructions (12). PCR was carried out in a DNA Thermal Cycler (Perkin Elmer-Cetus) according to the method of Russ et al. (35). The oligonucleotide sequences of the PCR primers were: 5'CAG GGT GCT GTC CAC ACT GGA CCC C$3^{\prime}$ and $5^{\prime} \mathrm{CCG}$ TTT GTG CAG GGC CTG GCT CTC T- $3^{\prime}$. The initial cycle consisted of heating to $94^{\circ} \mathrm{C}$ for $7 \mathrm{~min}$, followed by 45 cycles of $94^{\circ} \mathrm{C}$ for 1 $\min , 68^{\circ} \mathrm{C}$ for $1 \mathrm{~min}$, and $72^{\circ} \mathrm{C}$ for $1 \mathrm{~min}$, and a final cycle of $72^{\circ} \mathrm{C}$ for $10 \mathrm{~min}$. Aliquots $(4 \mathrm{ml})$ of the PCR products were digested with 6 units of Tth 111-I (Takara Shuzou Co., Ltd, Kyoto, Japan) at $65^{\circ} \mathrm{C}$ overnight. DNA fragments were separated by electrophoresis on $2.5 \%$ agarose gel in $40 \mathrm{mM}$ trisacetate/ $1 \mathrm{mM}$ ethylenediaminetetraacetic acid (EDTA, pH 7.7) containing $0.5 \mathrm{mg} / \mathrm{ml}$ ethidium bromide, and were visualized using ultraviolet light.

Identification of the ATG genotypes of all samples was made by a single investigator (S.N.) at the
Division of Genetics, International Center for Medical Research, Kobe University School of Medicine (Kobe, Japan) in a blinded manner.

\section{Determination of ACE I/D Genotype}

PCR was performed in a thermal reactor (MJ Research, Massachusetts, USA). The oligonucleotide sequences of the PCR primers were: $5^{\prime}$ CTG CAG ACC ACT CCC ATC CTT TCT 3' and 5' GAT GTG GCC ATC ACA TTC GTC AGA T 3' (36). The DNA was amplified for 35 cycles with denaturation at $94^{\circ} \mathrm{C}$ for $30 \mathrm{~s}$, annealing at $60^{\circ} \mathrm{C}$ for 30 $\mathrm{s}$, and extension at $70^{\circ} \mathrm{C}$ for $60 \mathrm{~s}$. The PCR products were separated by electrophoresis on $3 \%$ agarose gel (NuSieve 3:1 Agarose gel, FMC Bioproducts, Rockland, USA) in $45 \mathrm{mM}$ tris-borate, 1 mM EDTA ( $\mathrm{pH} 7.7$ ) containing $0.5 \mathrm{mg} / \mathrm{ml}$ ethidium bromide, and visualized using ultraviolet light.

To avoid mistyping, in the 33 samples identified as having DD genotype by the above method, the investigator (S.N.) conducted an insertion-specific second amplification using the insertion-specific primer of the oligonucleotide sequences of $5^{\prime}$ TGG 
Table 2. Office and $24 \mathrm{~h}$ BP in Hypertensives with Different ACE I/D Genotypes

\begin{tabular}{|c|c|c|c|c|}
\hline & & II & ID & DD \\
\hline \multicolumn{2}{|l|}{ Number } & 96 & 109 & 30 \\
\hline \multicolumn{2}{|l|}{ Age (yr) } & $72(8.3)$ & $68(10)$ & $71(9.0)$ \\
\hline \multicolumn{2}{|c|}{ Male $(\%)$} & 29 & 35 & 43 \\
\hline \multicolumn{2}{|c|}{ Body mass index $\left(\mathrm{kg} / \mathrm{m}^{2}\right)$} & $23.9(3.4)$ & $23.9(3.3)$ & $23.7(3.2)$ \\
\hline \multicolumn{2}{|c|}{ ECG-LVH $(\%)$} & 24 & 22 & 33 \\
\hline \multicolumn{2}{|c|}{ Smokers $(\%)$} & 39 & 24 & 33 \\
\hline \multicolumn{5}{|c|}{ Family history of hypertension } \\
\hline \multicolumn{2}{|c|}{ Either parent $(\%)$} & 35 & 40 & 57 \\
\hline \multicolumn{2}{|c|}{ Both parents (\%) } & 11 & 12 & 7 \\
\hline \multicolumn{5}{|c|}{ Family history of cardiovascular disease } \\
\hline \multicolumn{2}{|c|}{ Either parent $(\%)$} & 20 & 20 & 33 \\
\hline \multirow[t]{3}{*}{ Office } & $\mathrm{SBP}(\mathrm{mmHg})$ & $164(18)$ & $163(19)$ & $167(20)$ \\
\hline & DBP $(\mathrm{mmHg})$ & $92(13)$ & $93(12)$ & $97(13)$ \\
\hline & $\operatorname{HR}(/ \min )$ & 77 (11) & $78(16)$ & $80(17)$ \\
\hline \multirow[t]{3}{*}{ 24-h } & $\mathrm{SBP}(\mathrm{mmHg})$ & $142(15)$ & $140(12)$ & $149(15)^{*, \ddagger}$ \\
\hline & DBP $(\mathrm{mmHg})$ & $80(9.9)$ & $79(8.0)$ & $86(16)^{* *}$ \\
\hline & $\mathrm{HR}(/ \min )$ & $71(8.2)$ & $71(7.4)$ & $71(7.2)$ \\
\hline \multirow[t]{3}{*}{ Day } & $\mathrm{SBP}(\mathrm{mmHg})$ & $146(17)$ & $145(14)$ & $153(14)^{*, \dagger}$ \\
\hline & $\mathrm{DBP}(\mathrm{mmHg})$ & $83(11)$ & $83(9.1)$ & $88(9.8)^{*, \dagger}$ \\
\hline & $\mathrm{HR}(/ \min )$ & $77(8.9)$ & $77(8.0)$ & $77(8.2)$ \\
\hline \multirow[t]{3}{*}{ Night } & $\mathrm{SBP}(\mathrm{mmHg})$ & $134(16)$ & $130(15)$ & $141(20)^{*, \ddagger}$ \\
\hline & DBP $(\mathrm{mmHg})$ & $73(9.5)$ & $73(9.2)$ & $78(14)^{*, \dagger}$ \\
\hline & $\mathrm{HR}(/ \mathrm{min})$ & $62(8.2)$ & $61(9.0)$ & $61(6.0)$ \\
\hline \multirow[t]{3}{*}{ Night-lowest } & $\mathrm{SBP}(\mathrm{mmHg})$ & $117(16)$ & $114(20)$ & $124(21)^{\ddagger}$ \\
\hline & $\mathrm{DBP}(\mathrm{mmHg})$ & $66(11)$ & $65(11)$ & $70(15)$ \\
\hline & $\operatorname{HR}(/ \min )$ & $64(11)$ & $63(11)$ & $65(7.8)$ \\
\hline
\end{tabular}

Data for age and metabolic variable are shown as the mean (SD). ${ }^{*} p<0.05,{ }^{* *} p<0.01,{ }^{* * *} p<0.001, v s$. II genotype; ${ }^{\dagger} p$ $<0.05,{ }^{\ddagger} p<0.01, v s$. ID genotype by Scheffe's $F$-test.

GAC CAC AGC GCC CGC CAC TAC $3^{\prime}$ and 5' TCG CCA GCC CTC CCA TGC CCA TAA $3^{\prime}$ (37). By this means, 3 samples with ID genotype were identified as having been misclassified as DD.

\section{Statistical Analysis}

Data are expressed as the mean (SD) and percentages. One-way analysis of variance (ANOVA) was performed to detect differences among groups, and Scheffe's $F$-test was used for comparison between the mean values for pairs of groups. Allele frequencies in different groups were compared by gene counting and $\chi^{2}$ analysis. $P$ values $<0.05$ were considered significant.

\section{Results}

$A T G$ and $A C E$ Genotypes and BP Level

The distribution of the ATG and ACE genotypes was consistent with the sample being in HardyWeinberg equilibrium. There were no significant differences among the 3 groups with different ATG genotypes, or among the 3 groups with different ACE genotypes in clinical data, including family history of hypertension and cardiovascular diseases (coronary artery disease, stroke, and sudden death) or in office BP. Concerning the ATG genotype, the $24 \mathrm{~h}$ SBP was significantly higher in those with TT genotype than in those with MM genotype (Table 1). The day SBP and day DBP were significantly higher in those with TT genotype than in those with MT or with MM genotype, while there were no significant differences in night BP or night-lowest BP. Concerning the ACE genotype, the $24 \mathrm{~h} \mathrm{BP}$, day $\mathrm{BP}$, night $\mathrm{BP}$, and night-lowest $\mathrm{BP}$ were significantly higher in those with DD genotype than in those with II or with ID genotype (Table 2). There were no synergistic effects of ATG genotype and ACE genotype on BP levels (Table 3).

ATG, ACE Genotypes, White-Coat Hypertension, and Sustained Hypertension

When we divided the hypertensive subjects studied into white-coat hypertension and sustained hypertension groups based on $24 \mathrm{~h} \mathrm{BP}$, we found no significant differences between the 2 groups in the prevalence of ATG and ACE genotypes (Table 4). The derived gene frequency of the ATG T235 allele was significantly higher in the sustained hypertension group than in the white-coat hypertension group, and that of the ACE D allele tended to be higher, but not significantly so, in the former group. 
Table 3. Office and $24 \mathrm{~h}$ BP in Hypertensive Subgroups: 4 Combinations of ATG T/M and ACE I/D Genotypes

\begin{tabular}{|c|c|c|c|c|c|}
\hline & & Non-TT, non-DD & TT, non-DD & Non-TT, DD & TT, DD \\
\hline \multicolumn{2}{|l|}{ Number } & 89 & 116 & 18 & 12 \\
\hline \multicolumn{2}{|l|}{ Age (yr) } & $69(9.3)$ & $70(9.8)$ & $73(8.1)$ & $67(9.3)$ \\
\hline \multicolumn{2}{|c|}{ Male $(\%)$} & 30 & 34 & 33 & 58 \\
\hline \multicolumn{2}{|c|}{ Body mass index $\left(\mathrm{kg} / \mathrm{m}^{2}\right)$} & $23.3(3.4)$ & $24.3(3.2)$ & $22.9(3.4)$ & $24.8(2.5)$ \\
\hline \multicolumn{2}{|c|}{ ECG-LVH $(\%)$} & 29 & 18 & 33 & 33 \\
\hline \multicolumn{2}{|c|}{ Smoker $(\%)$} & 30 & 31 & 22 & 50 \\
\hline \multicolumn{2}{|c|}{ Family history of hypertension } & & & , & \\
\hline \multicolumn{2}{|c|}{ Either parent $(\%)$} & 33 & 42 & 61 & 50 \\
\hline \multicolumn{2}{|c|}{ Both parents (\%) } & 9 & 14 & 6 & 8 \\
\hline \multicolumn{6}{|c|}{ Family history of cardiovascular disease } \\
\hline \multicolumn{2}{|c|}{ Either parent $(\%)$} & 11 & $27 * *$ & $33 *$ & 33 \\
\hline \multirow[t]{3}{*}{ Office } & SBP (mmHg) & $161(17)$ & $166(20)$ & 169 (19) & $163(22)$ \\
\hline & DBP (mmHg) & $91(12)$ & $93(13)$ & $98(10)$ & $95(16)$ \\
\hline & $\mathrm{HR}(/ \min )$ & $78(13)$ & $78(14)$ & $82(21)$ & $76(8.9)$ \\
\hline \multirow[t]{3}{*}{ 24-h } & SBP (mmHg) & $138(16)$ & $143(12) *$ & $148(17)^{*}$ & $149(13)^{*}$ \\
\hline & DBP (mmHg) & $78(10)$ & $80(7.9)$ & $83(10) *$ & $89(22)^{*, \dagger}$ \\
\hline & $\mathrm{HR}(/ \min )$ & $72(7.7)$ & $71(7.8)$ & $69(6.7)$ & $74(7.0)$ \\
\hline \multirow[t]{3}{*}{ Day } & $\mathrm{SBP}(\mathrm{mmHg})$ & $141(17)$ & $150(13)^{*}$ & $153(15)^{*}$ & $153(13)^{*}$ \\
\hline & $\mathrm{DBP}(\mathrm{mmHg})$ & $80(10)$ & $85(9.1)^{*}$ & $88(9.7)^{*}$ & $87(10) *$ \\
\hline & $\mathrm{HR}(/ \min )$ & $76(6.5)$ & $77(8.4)$ & $75(7.1)$ & $80(9.2)$ \\
\hline \multirow[t]{3}{*}{ Night } & SBP (mmHg) & $130(18)$ & $133(14)$ & $138(20)$ & $146(21)^{*, \dagger}$ \\
\hline & $\mathrm{DBP}(\mathrm{mmHg})$ & $72(9.9)$ & $74(8.8)$ & $76(12)$ & $80(16)^{*, \dagger}$ \\
\hline & $\mathrm{HR}(/ \min )$ & $61(7.6)$ & $62(9.4)$ & $60(6.4)$ & $64(4.4)$ \\
\hline \multirow[t]{3}{*}{ Night-lowest } & $\mathrm{SBP}(\mathrm{mmHg})$ & $115(17)$ & $115(20)$ & $122(22)$ & 127 (19) \\
\hline & DBP $(\mathrm{mmHg})$ & $65(12)$ & $66(10)$ & $68(15)$ & $72(15)$ \\
\hline & $\mathrm{HR}(/ \min )$ & $64(11)$ & $63(11)$ & $62(6.0)$ & $69(8.2)$ \\
\hline
\end{tabular}

Data for age and metabolic variable are shown as the mean (SD). ${ }^{*} p<0.05,{ }^{* *} p<0.01,{ }^{* * *} p<0.001, v s$. non-TT/nonDD genotype; ${ }^{\dagger} p<0.01, v s$. TT/non-DD genotype by Scheffe's $F$-test.

Table 4. ATG T/M and ACE I/D Genotype Distributions and Gene Frequencies

\begin{tabular}{|c|c|c|c|}
\hline & \multirow{2}{*}{ Normotensive Group } & \multicolumn{2}{|c|}{ Hypertensive Group } \\
\hline & & White-coat hypertension & Sustained hypertension \\
\hline \multicolumn{4}{|l|}{ ATG T/M genotype, $n(\%)$} \\
\hline MM & $11(11)$ & $6(8)$ & $4(2)$ \\
\hline MT & $58(56)$ & $36(49)$ & $61(38)$ \\
\hline $\mathrm{TT}$ & $34(33)$ & $32(43)$ & $96(60)$ \\
\hline vs. Normotensive group & - & $\chi^{2}=1.98(\mathrm{NS})$ & $\chi^{2}=21.2(p<0.0001)$ \\
\hline vs. White-coat group & - & - & $\chi^{2}=7.69(p=0.021)$ \\
\hline ATG T235 allele frequency & 0.61 & 0.68 & 0.79 \\
\hline$v s$. Normotensive group & - & $\chi^{2}=1.53(\mathrm{NS})$ & $\chi^{2}=18.8(p<0.0001)$ \\
\hline$v s$. White-coat group & - & - & $\chi^{2}=6.57(p=0.010)$ \\
\hline ACE I/D genotype, $n(\%)$ & & . & \\
\hline II & $41(39)$ & $33(45)$ & $63(39)$ \\
\hline ID & $55(53)$ & $38(51)$ & $71(44)$ \\
\hline $\mathrm{DD}$ & $8(8)$ & $3(4)$ & $27(17)$ \\
\hline vs. Normotensive group & - & $\chi^{2}=1.22(\mathrm{NS})$ & $\chi^{2}=4.97(\mathrm{NS})$ \\
\hline$v s$. White-coat group & - & - & $\chi^{2}=7.37(p=0.025)$ \\
\hline ACE D allele frequency & 0.34 & 0.30 & 0.38 \\
\hline vs. Normotensive group & - & $\chi^{2}=0.767(\mathrm{NS})$ & $\chi^{2}=1.19(\mathrm{NS})$ \\
\hline vs. White-coat group & - & - & $\chi^{2}=3.64(p=0.057)$ \\
\hline
\end{tabular}

NS, not significant. 
Table 5. Office and $24 \mathrm{~h} \mathrm{BP}$ in Sustained Hypertensives with Different ATG T/M and ACE I/D Genotypes

\begin{tabular}{|c|c|c|c|c|}
\hline & & $\mathrm{MM}$ & MT & TT \\
\hline Number & & 4 & 61 & 96 \\
\hline \multirow[t]{2}{*}{ Office } & SBP (mmHg) & $164(22)$ & $169(18)$ & $168(20)$ \\
\hline & DBP $(\mathrm{mmHg})$ & 94 (12) & 97 (12) & 95 (14) \\
\hline \multirow[t]{2}{*}{$24 \mathrm{~h}$} & SBP (mmHg) & $142(6.9)$ & $150(12)$ & $149(10)$ \\
\hline & $\mathrm{DBP}(\mathrm{mmHg})$ & $81(2.6)$ & $79(8.8)$ & 84 (11) \\
\hline \multirow[t]{2}{*}{ Day } & SBP (mmHg) & $147(12)$ & $153(13)$ & $155(11)$ \\
\hline & $\mathrm{DBP}(\mathrm{mmHg})$ & $85(6.5)$ & $87(8.5)$ & $87(9.1)$ \\
\hline \multirow[t]{3}{*}{ Night } & $\mathrm{SBP}(\mathrm{mmHg})$ & $135(7.3)$ & $141(16)$ & $139(14)$ \\
\hline & DBP $(\mathrm{mmHg})$ & $76(3.1)$ & $78(9.5)$ & $77(10)$ \\
\hline & & II & ID & $\mathrm{DD}$ \\
\hline \multicolumn{2}{|l|}{ Number } & 63 & 71 & 27 \\
\hline \multirow[t]{2}{*}{ Office } & SBP (mmHg) & 169 (19) & $169(20)$ & $169(20)$ \\
\hline & $\mathrm{DBP}(\mathrm{mmHg})$ & 95 (13) & $96(13)$ & 97 (13) \\
\hline \multirow[t]{2}{*}{$24 \mathrm{~h}$} & SBP (mmHg) & $150(11)$ & $146(9.4)$ & $151(13)$ \\
\hline & $\mathrm{DBP}(\mathrm{mmHg})$ & $84(8.9)$ & $83(7.0)$ & 87 (16) \\
\hline \multirow[t]{2}{*}{ Day } & SBP (mmHg) & $155(13)$ & $152(11)$ & $156(12)$ \\
\hline & $\mathrm{DBP}(\mathrm{mmHg})$ & $87(9.2)$ & $87(8.3)$ & $89(9.3)$ \\
\hline \multirow[t]{2}{*}{ Night } & SBP (mmHg) & $141(13)$ & $137(14)$ & 144 (19) \\
\hline & $\mathrm{DBP}(\mathrm{mmHg})$ & $77(8.7)$ & $76(8.5)$ & $79(14)$ \\
\hline
\end{tabular}

Data are shown as the mean (SD).

Comparison with Normotensive Subjects

The ATG T235 allele frequency in 103 normotensive subjects was 0.61 , which was not significantly different from that of the white-coat hypertension group (0.68) (Table 4). The ATG T235 allele frequency in 54 hypertensive subjects in the previous community-based cohort study $(0.71)$ was not significantly different from that $(0.75)$ in the hypertensive patients in the present study, suggesting that the consecutive selection of hypertensive outpatients in this study was not biased. The T235 allele frequency $(0.79)$ in the sustained hypertensive group was significantly higher than that $(0.61)$ of the normotensive subjects $(p<0.0001)$.

Concerning ACE D I/D genotype, the D allele frequency in 104 normotensive subjects was 0.34 , which was intermediate between that $(0.30)$ of the white-coat hypertension group and that $(0.38)$ of the sustained hypertension group, and was not significantly different from either value.

ATG, ACE Genotypes, and Severity of Hypertension After exclusion of the white-coat hypertension group to study the association between ATG, ACE genotype and the severity of hypertension, we found no differences among the 3 groups with different ATG genotypes, or among the 3 groups with different $\mathrm{ACE}$ genotypes, and any $\mathrm{BP}$ parameter obtained by ABPM among 161 sustained hypertensive subjects (Table 5).
ATG, ACE Genotypes, and Diurnal BP Variation in Sustained Hypertension

After excluding the white-coat hypertension group, we allocated the sustained hypertensive subjects to 3 subgroups with different diurnal BP variation (extreme-dippers, dippers, and non-dippers). There were significant differences among the extreme-dippers, dippers, and non-dippers in ATG T235 allele frequency $\left(0.94,0.79\right.$, and 0.75 , respectively, $\chi^{2}=$ $6.24, p<0.05)$, but the differences among the 3 subgroups in ATG genotypes were marginal $(p<$ $0.1)$. There were no significant differences among the 3 groups in ACE genotype or in derived D allele frequency. Since the number of extreme-dippers was small, we combined the data for the extreme-dippers and dippers. The combined group showed no significant difference from the non-dippers in ATG T235 allele frequency $\left(\chi^{2}=3.70\right)$ or in ACE D allele frequency $\left(\chi^{2}=0.257\right)$.

\section{Discussion}

In this study, in 235 asymptomatic Japanese elderly subjects with hypertension (WHO Stages I-II), both the ATG T 235 and ACE D alleles were associated with elevated $24 \mathrm{~h}$ BP and day BP, while only the ACE D allele was associated with elevated night BP. There were no synergistic effects of ATG and ACE genotypes on BP.

There are few reports on the association of ATG M235T and ACE I/D genotypes with BP assessed by ABPM $(38,39)$. The $24 \mathrm{~h}$ SBP measured by ABPM in our patients with ATG TT or MT geno- 
type was significantly higher than that of patients with MM genotype. We found that many subjects diagnosed with hypertension based on office BP had white-coat hypertension. The inconsistent finding of previous studies on the association between ATG and hypertension (5-11) might be due to the inclusion of white-coat hypertensive subjects. In our previous study of a community-dwelling population, conducted in the same geographic area as the present study, the ATG T235 allele frequency was 0.61 in normotensive subjects and 0.71 in hypertensive subjects (12). The T235 allele frequency (0.68) in white-coat hypertensive subjects was similar to that $(0.61)$ of normotensive subjects, and that $(0.79)$ of sustained hypertensive subjects was significantly higher than either of these.

In our present study, we found that the $24 \mathrm{~h} \mathrm{SBP}$ and DBP levels were significantly higher in patients with ACE DD genotype than in those with II genotype or with ID genotype. This fiinding was unexpected, as Maeda et al. found no significant difference in ACE D allele frequency between normotensive subjects and hypertensive patients diagnosed by ABPM. Their study patients were living in an area (Ibaragi prefecture) far from the area of this study (39), and there was no cultural exchange. There are a few reports indicating a positive association between the D allele and BP $(20,23)$, but most reports do not support a positive association. Our finding showing a positive association between the D allele and higher BP levels might be due to the advanced age of the subjects. The mean ages of the groups of subjects in the study by Maeda et al., in which no association was found between ACE D allele and BP measured by ABPM, was $10-20 \mathrm{yr}$ younger than that in this study (39). In our study, asymptomatic hypertensive subjects were carefully selected based on clinical and laboratory test results, but their target organ damage might have been subclinically advanced. Though the ATG T235 allele was associated only with day BP, the ACE D allele was associated with day BP, night BP, and night-lowest BP. There are some reports that elevation of night BP is associated more strongly with subclinical target organ damage (silent cerebrovascular disease, microalbuminuria, and left ventricular hypertrophy) and poor prognosis in hypertensive patients than day BP (24-27). Furthermore, we have encountered hypertensive patients whose markedly reduced night BP level became elevated to near the day BP after minor reversible ischemic stroke (40). Thus, the subclinical target organ damage often found in elderly hypertensive patients might result in further elevation of BP, especially at night, and the positive association of the ACE D allele with $24 \mathrm{~h}$ BP, day BP, night BP, and night-lowest BP.

One recent study examined the association between ATG, ACE genotypes, and $24 \mathrm{~h}$ BP measured by ABPM in 114 Caucasians with established essential hypertension (38). In that study, neither the ATG nor ACE genotype was associated with the severity of hypertension. However, that study excluded white-coat hypertensive subjects with $24 \mathrm{~h}$
SBP/DBP $<135 / 85 \mathrm{mmHg}$. In our study, the gene frequencies of ATG T235 allele and ACE D allele were significantly higher in the sustained hypertension group than in the white-coat hypertension group. We also found that in the sustained hypertension group, the severity of hypertension was not associated with either the ATG or ACE genotype. Thus, neither the ATG M235T nor ACE I/D genotype seems to be associated with the severity of hypertension in either Japanese or Caucasian sustained hypertensives.

In the sustained hypertensive patients, abnormal diurnal BP patterns were not associated with either the ATG or ACE genotype. Hypertensive non-dippers without a nocturnal fall in BP have reportedly had more advanced target organ damage and poorer prognosis relative to dippers with an appropriate fall in nocturnal BP (24-27). Furthermore, we demonstrated, as other researchers have noted, that the hypertensive extreme-dippers with a marked nocturnal BP decrease have more advanced silent cerebrovascular disease (27). Thus, we speculated that these abnormal diurnal BP variations in hypertension might be partly associated with ATG or ACE genotypes, but the findings do not support this hypothesis.

A limitation of this study, was that the subjects were older. Thus, the relationships between $24 \mathrm{~h}$ $\mathrm{BP}$ and these gene alleles may partly be due to advanced target organ damage with aging. In addition, more recent reports have demonstrated the genderspecific relationship between BP and the ACE D allele $(41,42)$. In these studies, they found a positive correlation between BP and ACE D allele only in men. In our present study, we could not assess this gender-specific difference due to the relative small number of study subjects.

In conclusion, in elderly Japanese hypertensive individuals, both the ATG T 235 and ACE D alleles are associated with elevated $24 \mathrm{~h} \mathrm{BP}$ and day $\mathrm{BP}$, while only the ACE D allele is associated with elevated night $\mathrm{BP}$.

\section{References}

1. Walker WG, Whelton PK, Saito H, Russel RP, Hermann J: Relation between blood pressure and renin, renin substrate, angiotensin II, aldosterone and urinary sodium and potassium in 574 ambulatory subjects. Hypertension 1979; 1: 287-291.

2. Watt GCM, Harrap SB, Foy CJW, et al: Abnormalities of glucocorticoid metabolism and the renin angiotensin system: a four-corners approach to the identification of genetic determinants of blood pressure. J Hypertens 1992; 10: 473-482.

3. Gaillard I, Clauser E, Corvol P: Structure of human angiotensinogen gene. DNA 1989; 8: 87-99.

4. Gaillard-Sanchez I, Mattei MG, Clauser E, Corvol P: Assignment by in situ hybridization of the angiotensinogen gene to chromosome band $1 \mathrm{q} 4$, the same region as the human renin gene. Hum Genet 1990; 84: 341-343.

5. Jeunemaitre $\mathrm{X}$, Soubrier F, Kotelevtsev YV, et al: Molecular basis of human hypertension: role of angiotensinogen. Cell 1992; 71: 169-180.

6. Jeunemaitre X, Charru A, Chatellier G, et al: M235T 
variant of the human angiotensinogen gene in unselected hypertensive patients. J Hypertens 1993; 11 (Suppl 5): S80-S81.

7. Hata A, Namikawa C, Sasaki M, et al: Angiotensinogen as a risk factor for essential hypertension in Japan. J Clin Invest 1994; 93: 1285-1287.

8. Iwai N, Ohmichi N, Nakamura Y, Mitsunami K, Kinoshita M: Molecular variants of the angiotensinogen gene and hypertension in a Japanese population. Hypertens Res 1994; 17: 117-121.

9. Kamitani A, Rakugi H, Higaki J, et al: Association analysis of a polymorphism of the angiotensinogen gene with essential hypertension in Japanese. J Hum Hypertens 1994; 8: 521-524.

10. Caulfield M, Lavender P, Farrall M, et al: Linkage of the angiotensinogen gene to essential hypertension. N Engl J Med 1994; 330: 1629-1633.

11. Bennett CL, Schrader AP, Morris BJ: Cross-sectional analysis of Met $^{235} \rightarrow$ Thr variant of angiotensinogen gene in severe, familial hypertension. Biochem Biophys Res Commun 1993; 197: 833-839.

12. Nishiuma S, Kario K, Kayaba K, et al: Effect of the angiotensinogen gene Met $^{235} \rightarrow$ Thr variant on blood pressure and other cardiovascular risk factors in two Japanese populations. J Hypertens 1995; 13: 717-722.

13. Cambien F, Poirier O, Lecerf L, et al: Deletion polymorphism in the gene for angiotensin-converting enzyme is a potent risk factor for myocardial infarction. Nature 1992; 359: 641-644.

14. Cambien F, Soubrier F: The angiotensin-converting enzyme: molecular biology and implication of the gene polymorphism in cardiovascular diseases, in: Laragh JH, Brenner BM (eds): Hypertension: Pathology, Diagnosis, and Management. New York, Raven Press, 1995, pp1667-1682.

15. Nakai $\mathrm{K}$, Itoh $\mathrm{C}$, Miura $\mathrm{Y}$, et al: Deletion polymorphism of the angiotensin I-converting enzyme gene is associated with serum ACE concentration and increased risk for CAD in the Japanese. Circulation 1994; 90: 2199-2202.

16. Kario K, Kanai N, Saito K, Nago N, Matsuo T, Shimada $\mathrm{K}$ : Ischemic stroke and the gene for angiotensin-converting enzyme in Japanese hypertensives. Circulation 1996; 93: 1630-1633.

17. Jeunemaitre X, Lifton RP, Hunt SC, Williams RR, Lalouel J-M: Absence of linkage between the angiotensin converting enzyme locus and human essential hypertension. Nature Genetics 1992; 1: 72-75.

18. Schmidt S, van Hooft IMS, Grobbee DE, Ganten D, Ritz E: Polymorphism of the angiotensin I converting enzyme gene is apparently not related to high blood pressure: Dutch Hypertension and Offspring Study. $J$ Hypertens 1993; 11: 345-348.

19. Harrap SB, Davidson HR, Connor JM, Soubrier F, Corvol P, Fraser R: The angiotensin I converting enzyme gene and predisposition to high blood pressure. Hypertension 1993; 21: 455-460.

20. Zee RYL, Lou YK, Griffiths LR, Morris BJ: Association of a polymorphism of the angiotensin I-converting enzyme gene with essential hypertension. Biochem Biophys Res Commun 1992; 184: 9-15.

21. Higashimori $\mathrm{K}$, Zhao Y, Higaki J, et al: Association analysis of a polymorphism of the angiotensin converting enzyme gene with essential hypertension in the Japanese population. Biochem Biophys Res Commun 1993; 191: 399-404.

22. Morise T, Takeuchi Y, Takeda R: Angiotensin-converting enzyme polymorphism and essential hypertension. Lancet 1994; 343: 125.

23. Pickering TG: White coat hypertension, in: Laragh JH, Brenner BM (eds): Hypertension: Pathology, Di- agnosis, and Management. New York, Raven Press, 1995, pp1913-1927.

24. O'Brien E, Sheridan J, O'Malley K: Dippers and non-dippers. Lancet 1988; 13: 397 (letter).

25. Shimada K, Kawamoto A, Matsubayashi K, Nishinaga A, Kimura S, Ozawa T: Diurnal blood pressure variations and silent cerebrovascular damage in elderly patients with hypertension. J Hypertens 1992; 10: 875-878.

26. Verdecchia P, Porcellati C, Schillaci G, et al: Ambulatory blood pressure: an independent predictor of prognosis in essential hypertension. Hypertension 1994; 24: 793-801:

27. Kario K, Matsuo T, Kobayashi H, Imiya M, Matsuo M, Shimada K: Relation between nocturnal fall of blood pressure and silent cerebrovascular damage in elderly hypertensives: advanced silent cerebrovascular damage in extreme-dippers. Hypertension 1996; 27: $130-135$.

28. The Joint National Committee on Detection, Evaluation, and Treatment of High Blood Pressure: The fifth report of the Joint National Committee on Detection, Evaluation, and Treatment of High Blood Pressure. Arch Intern Med 1993; 153: 154-183.

29. Kario K, Nago N, Kuroda T, et al., on behalf of the JMS Cohort Study Group: Characteristics of the insulin resistance syndrome in a Japanese population: The Jichi Medical School (JMS) Cohort Study. Arterioscler Thromb Vasc Biol 1996; 16: 269-274.

30. Nago N, Kayaba K, Hiraoka J, et al: Lipoprotein (a) levels in the Japanese population: influence of age and sex, and relation to atherosclerotic risk factors: The Jichi Medical School Cohort Study. Am J Epidemiol 1995; 141: 815-821.

31. Maeda Y, Ikeda U, Ebata $\mathrm{H}$, et al: Angiotensin-converting enzyme gene polymorphism in hypertensive individuals with parental history of stroke. Stroke 1996; 27: 1521-1523.

32. Sokolow M, Werdegar D, Kain HK, Hinman AT: Relationship between level of blood pressure measured casually and by portable recorders and severity of complications in essential hypertension. Circulation 1966; 34: 279-298.

33. White WB, Lund-Johansen P, McCabe EJ: Clinical evaluation of the Colin ABPM 630 at rest and during exercise: an ambulatory blood pressure monitor with gas-powered cuff inflation. J Hypertens 1989; 7: 477483.

34. Kanai N, Fujii T, Saito K, Yokoyama T: Rapid and simple method for preparation of genomic DNA from easily obtainable clotted blood. J Clin Pathol 1994; 47: 1043-1044.

35. Russ AP, Maerz W, Ruzicka V, Stein U, Grob W: Rapid detection of the hypertension-associated Met $^{235} \rightarrow$ Thr allele of the human angiotensinogen gene. Hum Mol Genet 1993; 2: 609-610.

36. Rigat B, Hubert C, Corvol P, Soubrier F: PCR detection of the insertion/deletion polymorphism of human angiotensin converting enzyme gene (DCP1) (dipeptidyl carboxypeptidase 1). Nucleic Acids Res 1992; 20: 1433.

37. Lindpaintner K, Pfeffer MA, Kreutz R, et al: A prospective evaluation of an angiotensin-converting-enzyme gene polymorphism and the risk of ischemic heart disease. $N$ Engl J Med 1995; 332: 706-711.

38. Beige J, Zilch $\mathrm{O}$, Hohenbleicher $\mathrm{H}$, et al: Genetic variants of the renin-angiotensin system and ambulatory blood pressure in essential hypertension. $J$ Hypertens 1997; 15: 503-508.

39. Maeda Y, Ikeda U, Ebata H, et al: Angiotensin converting enzyme gene polymorphism in essential 
hypertension based on ambulatory blood pressure monitoring. Am J Hypertens 1997; 10: 786-789.

40. Kario K, Shimada K: Change in diurnal blood pressure rhythm due to small lacunar infarct. Lancet 1994; 344: 200 (letter).

41. O'Donnell CJ, Lindpainter $\mathrm{K}$, Larson MG, et al: Evidence for association and genetic linkage of the angiotensin-converting enzyme locus with hyperten- sion and blood pressure in men but not women in the Framingham Heart Study. Circulation 1998; 97: 1766-1772.

42. Fornage M, Amos CI, Kardia S, Sing CF, Tuner ST, Boerwinkle E: Variation in the region of the angiotensin-converting enzyme gene influences individual differences in blood pressure levels in young white males. Circulation 1998; 97: 1773-1779. 